\title{
O ensino remoto no curso de Medicina de uma universidade brasileira em tempos de pandemia
}

\author{
Remote education at Brazilian university medical school during the pandemic
}

\author{
Amadeu Sá de Campos Filho' (1) amadeu.campos@ufpe.br \\ João Marcelo Duarte Ribeiro Sobrinho' (D) joao.mdrsobrinho@ufpe.br \\ Ricardo Fusano Romão ${ }^{1}$ (D) ricardo.fusano@ufpe.br \\ Carlos Henrique Nascimento Domingues da Silva' (D) carlos.domingues@ufpe.br \\ Júlio Cesar Pereira Alves ${ }^{1}$ (D) julio.cesaralves@ufpe.br \\ Rodrigo Lins Rodrigues ${ }^{2}$ (D) rodrigomuribec@gmail.com
}

\section{RESUMO}

Introdução: O processo de ensino-aprendizagem passou por grandes mudanças tecnológicas ao longo das décadas, com importante impacto nos cursos de Medicina. Uma dessas mudanças foi o uso dos ambientes virtuais de aprendizagem (AVA).

Objetivo: Este estudo teve como objetivo avaliar a qualidade do processo de ensino-aprendizagem remoto no curso de Medicina durante a pandemia da Covid-19.

Método: É um estudo de caráter descritivo com abordagem quantitativa e qualitativa. Seu desenvolvimento foi dividido em quatro fases: revisão da literatura, desenvolvimento do protocolo de avaliação, coleta e análise dos dados. A coleta de dados foi realizada por meio de um formulário on-line, e a análise dos dados, por análise estatística em três eixos: a avaliação do perfil tecnológico, a avaliação da aceitação da tecnologia e a experiência do usuário.

Resultado: Foi constatado que a maioria dos estudantes (65\%) e docentes (88.2\%) possuía infraestrutura para participar do semestre suplementar. A maior parte dos alunos relatou sentir segurança em utilizar as ferramentas tecnológicas e estava satisfeita com o ensino remoto, porém $53 \%$ dos alunos relataram não ter um rendimento tão grande quanto teriam em um período presencial comum, além de terem mencionado dificuldades na adaptação ao ensino remoto, e 40,2\% citaram uma alta taxa de problemas psicológicos entre eles. Os docentes em sua maioria se sentiam seguros em lecionar on-line e também tiveram uma avaliação em geral bastante positiva do semestre remoto, tendo apenas algumas discordâncias em relação ao tempo para preparação das aulas e da criação de materiais didáticos para seus alunos.

Conclusão: Os diversos fatores relacionados à tecnologia, organização e saúde mental dos estudantes e docentes devem ser levados em consideração no planejamento dos próximos semestres, pois, até que a situação de saúde volte ao normal, os próximos semestres letivos terão todos os componentes teóricos do curso de Medicina trabalhados remotamente, ao menos com a maioria na modalidade híbrida. É provável que alunos e professores desenvolvam uma curva de aprendizagem e consequente adaptação, o que pode atenuar algumas das dificuldades observadas. É preciso que o processo de adaptação seja catalisado por normas, orientações e também inovações da universidade.

Palavras-chave: Educação Médica; Educação a Distância; Covid-19; Avaliação Educacional.

\begin{abstract}
Introduction: Introduction: The teaching-learning process has undergone major technological changes over the decades, with a significant impact on medical courses. One of these changes has been the use of virtual learning environments (VLES).

Objective: to evaluate the quality of the remote teaching-learning process in the medical course during the COVID-19 pandemic.

Method: This is a descriptive study with a quantitative and qualitative approach. Its development was divided into 4 phases: literature review, development of the assessment protocol, data collection and analysis. Data collection was through an online form and data analysis was by statistical analysis on three axes: assessment of the technological profile, assessment of the acceptance of the technology and the user experience.

Result: It was found that most students (65\%) and teachers (88.2\%) had the infrastructure to participate in the supplementary semester. Most students reported feeling safe in using technological tools and were satisfied with the remote teaching, however, 53\% of students reported underachievement in relation to their performance in an ordinary classroom period and reported difficulties in adapting to remote learning, and $40.2 \%$ reported a high rate of psychological problems. Most teachers felt secure in teaching online and had a very positive overall evaluation of the remote semester, with only a few disagreements regarding the time to prepare classes and create teaching materials for their students.
\end{abstract}

Conclusion: The various factors related to technology, organization and mental health of students and teachers must be taken into account in the planning of the next semesters, because until the health situation returns to normal, the forthcoming academic semesters will provide all the theoretical components of the medical course remotely, or at least the majority provided in a hybrid modality. It is likely that students and teachers will develop a learning curve and consequent adaptation, which may alleviate some of the difficulties observed. The adaptation process needs to be catalyzed by standards, guidelines and innovations from the university.

Keywords: Medical Education; Distance Education; COVID-19; Educational Measurement.

${ }^{1}$ Universidade Federal de Pernambuco, Recife, Pernambuco, Brasil.

${ }^{2}$ Universidade Federal Rural de Pernambuco, Recife, Pernambuco, Brasil.

Editora-chefe: Rosiane Viana Zuza Diniz. | Editor associado: Fernando Antonio de Almeida.

Recebido em 04/11/21; Aceito em 11/12/21. | Avaliado pelo processo de double blind review. 


\section{INTRODUÇÃO}

Com o passar do tempo, o processo de ensinoaprendizagem passou por várias mudanças importantes. Uma dessas mudanças ocorreu com o surgimento do modelo construtivista de educação, pois a figura do professor deixou de ser o centro do saber e o aluno tornou-se também o protagonista do processo de ensino-aprendizagem ${ }^{1,2}$. Além disso, de acordo com as Diretrizes Curriculares Nacionais (DCN) do curso de graduação em Medicina ${ }^{3}$, uma das competências do médico egresso é a educação permanente, o que implica a construção ativa do seu conhecimento por meio do processo de aprender a aprender. Essas mudanças têm se refletido no curso de Medicina, principalmente pela reestruturação curricular e adoção de metodologias ativas como o Aprendizado Baseado em Problemas (APB). Além disso, apesar do horizonte de mudança, a maioria das instituições de ensino superior tem um ensino ainda tradicional centrado no professor como detentor do conhecimento.

No contexto da aprendizagem ativa dos cursos de Medicina e com a evolução das tecnologias educacionais, os professores e estudantes tiveram que se adequar às novas metodologias do processo de ensino-aprendizagem por meio da incorporação das tecnologias digitais como suporte ao ensino presencial ${ }^{4}$. No entanto, essa adequação se torna ainda mais desafiadora para um curso de Medicina, uma vez que 1. a medicina é uma área que tem forte apelo pelo contato direto humano e 2. há uma discrepância geracional com estudantes que se habituaram desde cedo com as Tecnologias de Informação e Comunicação (TICs) e professores que não tiveram o mesmo processo em suas formações. Além disso, a deficiente capacitação dos professores e estudantes para uso das TIC na educação e o excessivo uso de artefatos educacionais estáticos, como apostilas, utilizados de forma assíncrona, que permitem pouca interatividade entre o aluno e o professor, também devem ser levados em conta ${ }^{5}$.

Existem algumas ferramentas usadas para melhorar a interatividade entre docentes e discentes na educação mediada por tecnologia, como os Ambientes Virtuais de Aprendizagem (AVAs) ${ }^{2}$. Eles surgiram para mediar o processo ensino-aprendizagem a distância, mas têm importante impacto também na modalidade presencial, por exemplo: 1. permitem disponibilizar um repositório de conteúdos e objetos de aprendizagem; 2. facilitam e ampliam a comunicação docentediscente; 3. possibilitam a realização de atividades extraclasse; e 4. melhoram o gerenciamento e o acompanhamento do processo de ensino-aprendizagem. Assim, a educação médica pode ser bastante beneficiada pela adoção de AVA, permitindo uma maior interação docente-discente, a integração ensino-serviço ${ }^{6,7}$ e a adoção de práticas modernas no currículo de Medicina.
Nesse cenário de mudanças tecnológicas e preocupado com a melhoria da qualidade do ensino-aprendizagem, o curso de Medicina da Universidade Federal de Pernambuco (Ufpe) vem realizando ativamente discussões que envolveram as atividades do curso e a melhoria do desempenho dos alunos com vistas à qualidade do ensino. No segundo semestre de 2009, uma dessas melhorias foi efetivada com a estratégia proposta pelos professores de Informática em Saúde do Núcleo de Telessaúde (Nutes), em parceria com o Núcleo Pedagógico do Curso de Medicina, de ampliar essa inserção com a implantação pioneira no Norte-Nordeste de um AVA para o curso de Medicina chamado de AVAMED. O AVAMED tem a finalidade de se constituir como a ferramenta formal de aprendizado virtual do curso, contribuindo na reforma curricular ao introduzir novas metodologias que favorecem o processo ensino-aprendizado.

Além disso, a utilização das tecnologias educacionais na educação ficou mais evidente atualmente devido ao surgimento da pandemia da coronavirus disease 2019 (Covid-19) e com a necessidade de se manter o distanciamento social, em razão da quarentena. Nesse cenário, em março de 2020, a Ufpe decidiu suspender suas atividades alinhada com as determinações dos organismos de saúde e sanitários como a Organização Mundial da Saúde (OMS). Para não prejudicar o processo de ensinoaprendizagem dos alunos e não atrasar o cronograma do ano letivo, foi iniciada uma série de debates para discutir o uso do ensino totalmente remoto diante da quarentena.

Como resultado das discussões, propôs-se a criação de um semestre suplementar - 2020.3 - por meio do ensino remoto com o uso de tecnologias educacionais e de caráter opcional em agosto de 2020 por meio dos Estudos Continuados Emergenciais (ECE). No caso do semestre suplementar, que era opcional, o aluno poderia fazer o cancelamento de uma disciplina a posteriori e a exclusão de uma reprovação do histórico escolar dele. Além disso, a Ufpe não obrigou os professores a usar um AVA específico, deixando-os livres para escolher o ambiente mais adequado para cada disciplina. Nesse sentido, os ambientes mais utilizados no curso de Medicina foram o Classroom e o AVAMED (customização do Moodle), além de outras ferramentas do pacote Google G Suite. Assim, este trabalho objetiva avaliar a qualidade do processo de ensino-aprendizagem remoto no curso de Medicina da Ufpe durante a pandemia da Covid-19.

\section{MÉTODO}

O estudo aqui apresentado é de caráter descritivo com abordagem quantitativa e qualitativa. Trata-se de um estudo transversal realizado no ensino remoto do curso de Medicina da Ufpe durante a pandemia da Covid-19, no semestre 
suplementar de 2020.3. O desenvolvimento do estudo foi dividido em quatro fases, que consistiram em: revisão da literatura, desenvolvimento do protocolo de avaliação, coleta e análise dos dados. O estudo iniciou-se com uma pesquisa na literatura de maneira narrativa, com o intuito de investigar e identificar o contexto do ensino remoto no Brasil, sobretudo no que diz respeito à graduação em Medicina, bem como encontrar os melhores protocolos que versam sobre os critérios de avaliação das tecnologias empregadas no ensino remoto.

Após a revisão da literatura, definiu-se o protocolo de avaliação por meio da construção da primeira versão do formulário. Para validá-lo, realizaram-se várias reuniões e consultas aos especialistas na área de tecnologias educacionais. Este trabalho coletou respostas entre 25 de setembro de 2020 e 15 de dezembro de 2020.

\section{Local do estudo}

O estudo foi realizado no contexto do ensino remoto do curso de Medicina da Ufpe, no período suplementar de 2020.3, no qual se utilizaram oficialmente o AVAMED (Moodle) e o Google Classroom. Após autorização formal de aplicação do formulário de avaliação pela coordenação do curso de Medicina e da aprovação no Comitê de Ética, todos os estudantes e professores do Centro de Ciências Médicas (CCM) da Ufpe receberam uma mensagem de texto via aplicativo de comunicação móvel, com instruções para participar de forma anônima e espontânea da pesquisa.

\section{Amostra de participantes}

A amostra do estudo foi composta por 42 docentes e 546 discentes que participaram do semestre suplementar remoto de 2020.3 do curso de Medicina da Ufpe.

\section{Instrumentos de coleta de dados}

$O$ instrumento utilizado para coleta de dados foi um formulário estruturado no Google Forms, dividido em três seções. Na primeira seção, o participante teve de responder se concordava ou não com a sua participação na pesquisa, a partir do preenchimento do Termo de Consentimento Livre e Esclarecido (TCLE). Em seguida, foi questionado sobre o perfil acadêmico do participante. Na segunda seção, buscou-se traçar um perfil sociodemográfico do participante, a partir de informações como: quantas e quais disciplinas está cursando/ ministrando no semestre remoto; período (se estudante); gênero; e idade. Na última seção, foram questionados aspectos relativos ao processo de ensino-aprendizagem, a fim de avaliar os desafios enfrentados na participação no ensino remoto.

\section{Procedimentos para a coleta de dados}

Coletaram-se os dados por meio de um formulário estruturado no Google Forms. O link (endereço eletrônico) do formulário foi enviado por e-mail e também nos grupos das disciplinas em aplicativos de conversação pela coordenação do curso. Os dados sobre o perfil tecnológico dos estudantes e professores foram fornecidos pela coordenação do curso de Medicina, que já havia realizado um formulário acerca do perfil tecnológico dos docentes e alunos na primeira metade de 2020, antes do início do semestre suplementar remoto.

\section{Análise e interpretação dos dados}

A análise e a interpretação dos dados foram divididas em dois eixos: a avaliação do perfil tecnológico e a avaliação dos aspectos relativos ao processo de ensino-aprendizagem. A avaliação do perfil tecnológico foi feita por meio de um formulário realizado pela coordenação do curso de Medicina no início da pandemia, na primeira metade de 2020. Esse formulário tinha como objetivos traçar o perfil tecnológico dos discentes e docentes do curso de Medicina da Ufpe, levantando as características e dificuldades do uso das tecnologias educacionais, e embasar o desenvolvimento do ensino remoto.

Os dados do primeiro questionário sobre o perfil tecnológico dos docentes e alunos foram compilados em planilhas Excel, que foram então importadas para o programa R Studio, onde então se realizou o teste do qui-quadrado dos dados utilizando o pacote StringR para medir a associação entre duas variáveis categóricas. Realizou-se o teste nas variáveis "equipamentos eletrônicos", "ambiente físico adequado para EaD", "conhecimento de plataformas digitais", "experiência prévia em EaD", "afazeres domésticos inviabilizam o EaD" e "favorável ao ensino remoto", todas elas em relação à categoria de "perfil do participante", assim comparando as associações entre as variáveis e professores e alunos. Os dados do segundo questionário foram analisados por meio de técnicas da estatística descritiva, com enfoque na visualização dos dados por meio da utilização do pacote ggplot na linguagem $\mathrm{R}$.

Compilaram-se os resultados em planilhas Excel. A filtragem e limpeza dos dados foram realizados a partir da linguagem $R$, com a utilização do pacote Dplyr, excluindo resultados nulos, repetidos, docentes que não participaram do semestre suplementar e alunos de outros cursos; os gráficos de escalas foram feitos com o uso do pacote Likert. Os dados são apresentados de forma descritiva.

\section{Aspectos éticos}

Antes da coleta dos dados, realizou-se a submissão do projeto ao Comitê de Ética em Pesquisa do Centro de Ciências da Saúde da Ufpe. Aprovado sob Certificado de Apresentação 
para Apreciação Ética (CAAE) n 26807019.0.0000.5208 (Parecer no 3.824.597), foi dado prosseguimento com a realização da coleta dos dados.

\section{RESULTADOS}

O formulário sobre o perfil tecnológico foi aplicado a todos os alunos do curso de Medicina da Ufpe na primeira metade de 2020. Dos 760 estudantes, $467(61,44 \%)$ responderam ao questionário. Dos 42 professores que lecionaram no semestre suplementar, 17 (40,48\%) responderam ao questionário. A Tabela 1 apresenta a correlação entre as seguintes variáveis: equipamentos, se o ambiente físico é adequado para o ensino a distância (EaD), conhecimentos de plataformas digitais, experiência prévia em EaD, afazeres domésticos inviabilizam o EaD e se é favorável ao ensino remoto. Evidenciou-se correlação estatisticamente significativa entre conhecimento de plataformas digitais, experiência prévia em EaD e afazeres domésticos inviabilizam o $\operatorname{EaD}(p<0,05)$. As variáveis sem evidências de correlação estatisticamente significativa foram equipamentos, ambiente físico adequado para $\mathrm{EaD}$ e se era favorável ao ensino remoto. As variáveis de equipamentos e ambiente físico adequado para EaD não foram evidenciadas como correlações estatisticamente significativas porque as condições financeiras dos discentes e docentes são distintas. Já a variável ser favorável ao ensino remoto não teve correlação porque a maioria dos professores da Ufpe considerou que o curso de Medicina precisa ser $100 \%$ presencial, além de eles nunca terem tido experiência em ensino remoto.

\section{Perfil tecnológico}

Alunos

Nas respostas analisadas, foi observado que 450 (96,36\%) alunos possuem um notebook ou computador de mesa, e 448 $(95,9 \%)$ têm acesso à internet em casa por banda larga (via cabo ou roteador Wi-fi). De acordo com os recursos tecnológicos dos discentes, podemos observar que o acesso ao ensino remoto não seria um problema para os discentes, pois a maioria possuía algum equipamento e acesso à internet. Em relação ao uso de ferramentas, apenas 14 (3\%) se sentiam inseguros no uso de dispositivos e recursos digitais, e 308 (66\%) alunos já tinham na época participado de algum curso on-line. $\mathrm{O}$ baixo índice de insegurança em utilizar novas tecnologias por meio de dispositivos e recursos digitais não é um fator que impossibilita o sucesso de um ensino remoto, pois, segundo Campos Filho, Novaes e Gomes ${ }^{8}$,

Tabela 1. Correlações de perfil do participante.

\begin{tabular}{|c|c|c|c|c|c|c|}
\hline & & \multicolumn{4}{|c|}{ Perfil do participante } & \multirow{3}{*}{ Valor de $\mathrm{P}$} \\
\hline & & \multicolumn{2}{|c|}{ Aluno } & \multicolumn{2}{|c|}{ Professor } & \\
\hline & & Frequência & $\%$ & Frequência & $\%$ & \\
\hline \multirow{4}{*}{ Equipamentos } & Computador de mesa & 87 & $18,60 \%$ & 7 & $41,17 \%$ & \multirow{4}{*}{0,35} \\
\hline & Notebook & 433 & $92,70 \%$ & 16 & $94,11 \%$ & \\
\hline & Smartphone & 440 & $94,20 \%$ & 17 & $100 \%$ & \\
\hline & Tablet & 120 & $25,69 \%$ & 6 & $35,30 \%$ & \\
\hline \multirow{2}{*}{$\begin{array}{l}\text { Ambiente físico adequado } \\
\text { para EaD }\end{array}$} & Sim & 405 & $86,72 \%$ & 13 & $76,47 \%$ & \multirow{2}{*}{0,3952} \\
\hline & Não & 62 & $13,28 \%$ & 4 & $23,52 \%$ & \\
\hline \multirow{7}{*}{$\begin{array}{l}\text { Conhecimento de } \\
\text { plataformas digitais }\end{array}$} & Moodle - básico & 182 & $38,97 \%$ & 2 & $11,76 \%$ & \multirow{7}{*}{$2,2 \mathrm{e}-16$} \\
\hline & Moodle - intermediário & 86 & $18,41 \%$ & 3 & $17,64 \%$ & \\
\hline & Moodle - avançado & 32 & $6,85 \%$ & 0 & $0 \%$ & \\
\hline & G Suite - básico & 208 & $44,53 \%$ & 5 & $29,41 \%$ & \\
\hline & G Suite - Intermediário & 111 & $23,76 \%$ & 3 & $17,64 \%$ & \\
\hline & G Suite - avançado & 47 & $10,06 \%$ & 1 & $5,88 \%$ & \\
\hline & Nenhum deles & 88 & $18,84 \%$ & 8 & $47,05 \%$ & \\
\hline \multirow{2}{*}{ Experiência prévia em EaD } & Sim & 308 & $65,95 \%$ & 6 & $35,29 \%$ & \multirow{2}{*}{0,01915} \\
\hline & Não & 159 & $34,05 \%$ & 11 & $64,70 \%$ & \\
\hline \multirow{2}{*}{$\begin{array}{l}\text { Afazeres domésticos } \\
\text { inviabilizam o EaD }\end{array}$} & Sim & 48 & $10,27 \%$ & 6 & $35,29 \%$ & \multirow{2}{*}{0,004715} \\
\hline & Não & 419 & $89,73 \%$ & 11 & $64,70 \%$ & \\
\hline \multirow{2}{*}{ Favorável ao ensino remoto } & Sim & 286 & $61,24 \%$ & 11 & $64,70 \%$ & \multirow{2}{*}{0,9724} \\
\hline & Não & 181 & $38,76 \%$ & 6 & $35,29 \%$ & \\
\hline
\end{tabular}

Fonte: Elaborada pelos autores. 
existe uma curva de aprendizado no uso de novas tecnologias para qualquer pessoa, e, depois dessa curva de aprendizado, os usuários se sentem seguros e satisfeitos em usar esses recursos.

\section{Professor}

Similar aos alunos, a grande maioria dos professores avaliados, 16 (94,1\%), possui um notebook ou computador de mesa, novamente $16(94,1 \%)$ também relataram ter internet apropriada em sua moradia (com conexão livre e sem restrição de tempo de uso) para atividades remotas como aulas e reuniões.

Em relação às dificuldades encontradas pelos docentes, $13(76 \%)$ assinalaram que têm em sua moradia um ambiente apropriado para elaborar, gravar e ministrar aulas on-line. Em contrapartida, de forma significativa, seis (35\%) professores afirmaram ter uma rotina de isolamento e trabalho remoto que inclui afazeres domésticos e/ou cuidados com crianças, o que inviabiliza preparar ou ministrar aulas on-line.
Em relação à experiência em lecionar on-line, 9 (52,9\%) professores já tinham ministrado aulas on-line antes do início do período remoto, e 15 (88,2\%) se consideravam capazes de ministrar aulas a distância.

\section{Análise do aprendizado, satisfação e dificuldades}

A avaliação da qualidade do aprendizado, da satisfação e das dificuldades dos alunos de Medicina sobre o ensino remoto foi realizada apenas com os discentes e professores que participaram do semestre suplementar 2020.3 por meio de um questionário utilizando uma escala Likert de 5 pontos.

\section{Aluno}

Dos 546 estudantes, apenas 281 responderam ao formulário sobre diferentes aspectos, como demonstrado nos Gráficos 1 e 2.

De acordo com o Gráfico 1, podemos notar que, em relação à aprendizagem no ensino remoto, apesar de grande parte dos

Gráfico 1.Avaliação do ensino remoto pelos alunos.

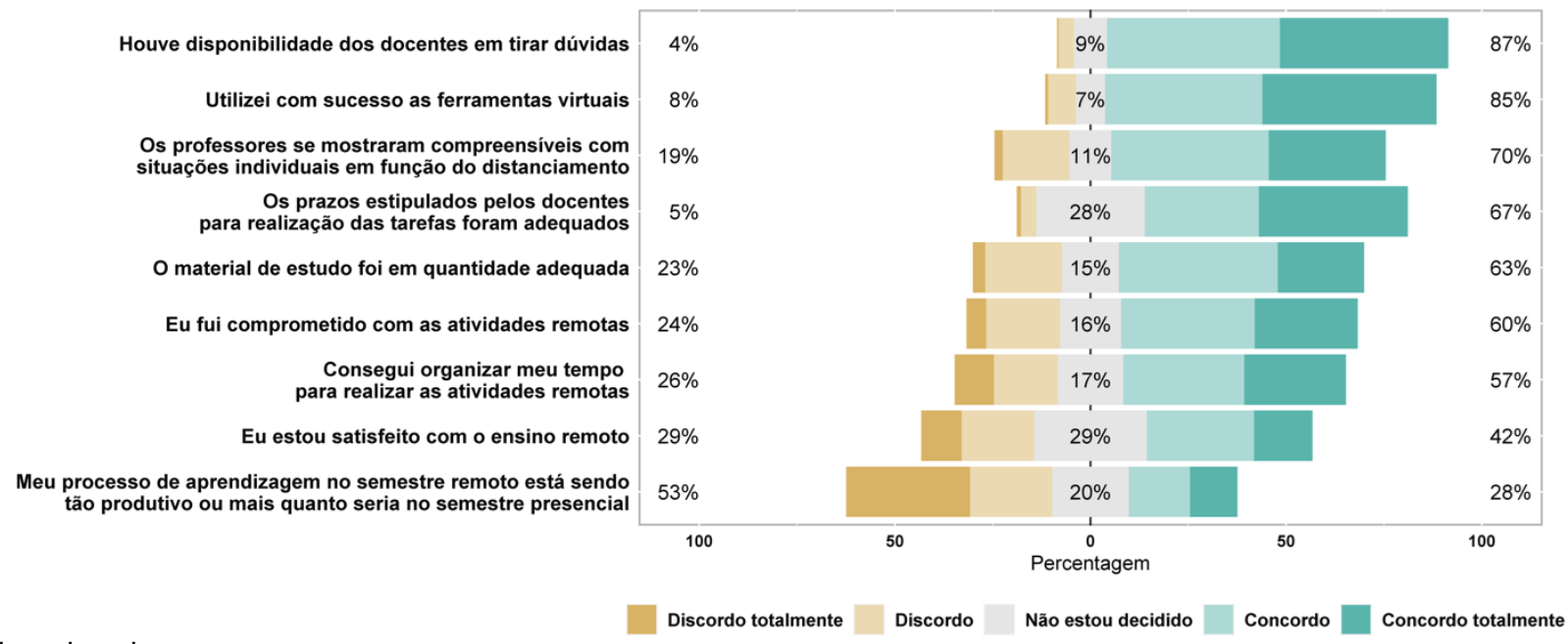

Fonte: Elaborado pelos autores.

Gráfico 2.Desafios encontrados pelos alunos no ensino remoto.

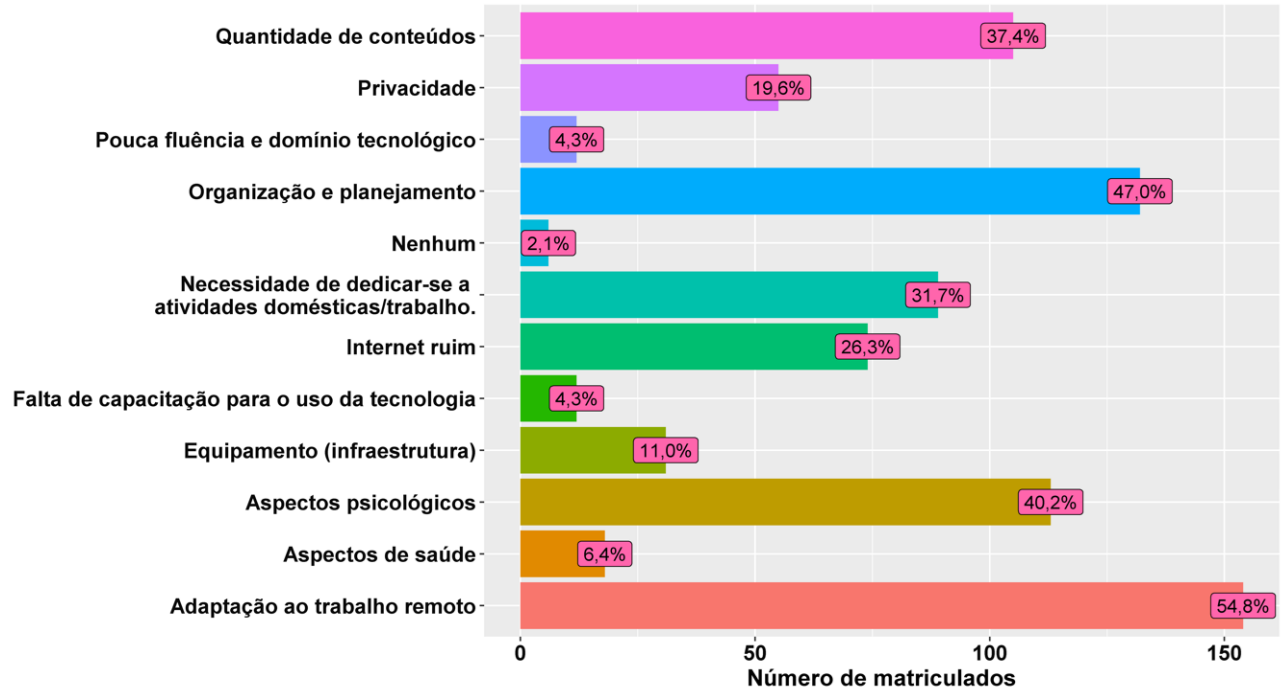

Fonte: Elaborado pelos autores. 
alunos ter avaliado positivamente diversos aspectos do período remoto e apenas 82 (29\%) participantes estarem insatisfeitos com essa modalidade de ensino, a maior parte, 149 (53\%), relatou ter seu processo de aprendizagem menos produtivo quando comparado ao semestre presencial. Outro aspecto importante observado foi o fato de que a grande maioria dos estudantes, 239 (85\%), utilizou com sucesso as ferramentas virtuais.

Em relação aos desafios encontrados pelos alunos no ensino remoto, podemos destacar quatro principais, conforme mostrado no Gráfico 2: adaptação ao trabalho remoto $(54,8 \%)$, organização e planejamento (47\%), aspectos psicológicos (40,2\%) e quantidade de conteúdo (37,4\%). Além disso, nota-se também a presença de diversos outros desafios, como necessidade de dedicar-se às atividades domésticas e internet ruim. Os alunos não demonstraram grandes índices de dificuldades na fluência e no domínio da tecnologia (4,3\%) e nem na falta de capacitação em seu uso (4,3\%).
Antes do início do semestre remoto, houve algumas dificuldades que foram reportadas pelos discentes e docentes devido ao trabalho remoto e ao distanciamento social. De acordo com os resultados, em relação ao ambiente de estudo, apenas 62 (13\%) alunos relataram não ter um local adequado para assistir às aulas e desenvolver uma rotina de estudos. Além disso, 48 (10\%) estudantes assinalaram ter uma rotina de afazeres domésticos ou cuidados com crianças, idosos ou outras pessoas que inviabilizam assistir às aulas on-line.

\section{Professor}

Dos 42 professores que lecionaram no semestre de 2020.3, apenas 18 responderam ao formulário. O Gráfico 3 mostra a avaliação do ensino remoto em relação à organização, qualidade, suporte e satisfação.

Percebe-se no Gráfico 3 que a avaliação foi majoritariamente positiva em todos os aspectos avaliados.

Gráfico 3.Avaliação do ensino remoto pelos docentes.

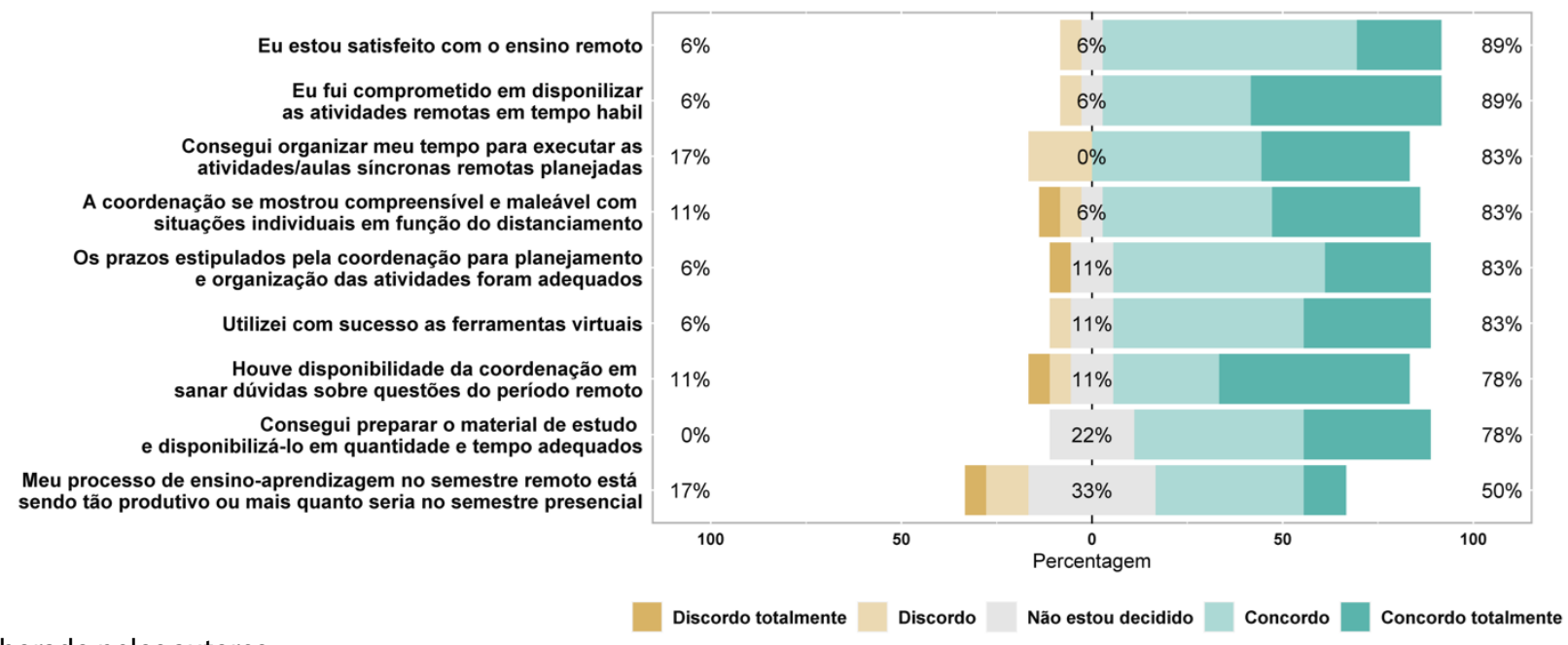

Fonte: Elaborado pelos autores.

Gráfico 4.Desafios encontrados pelos professores no ensino remoto.

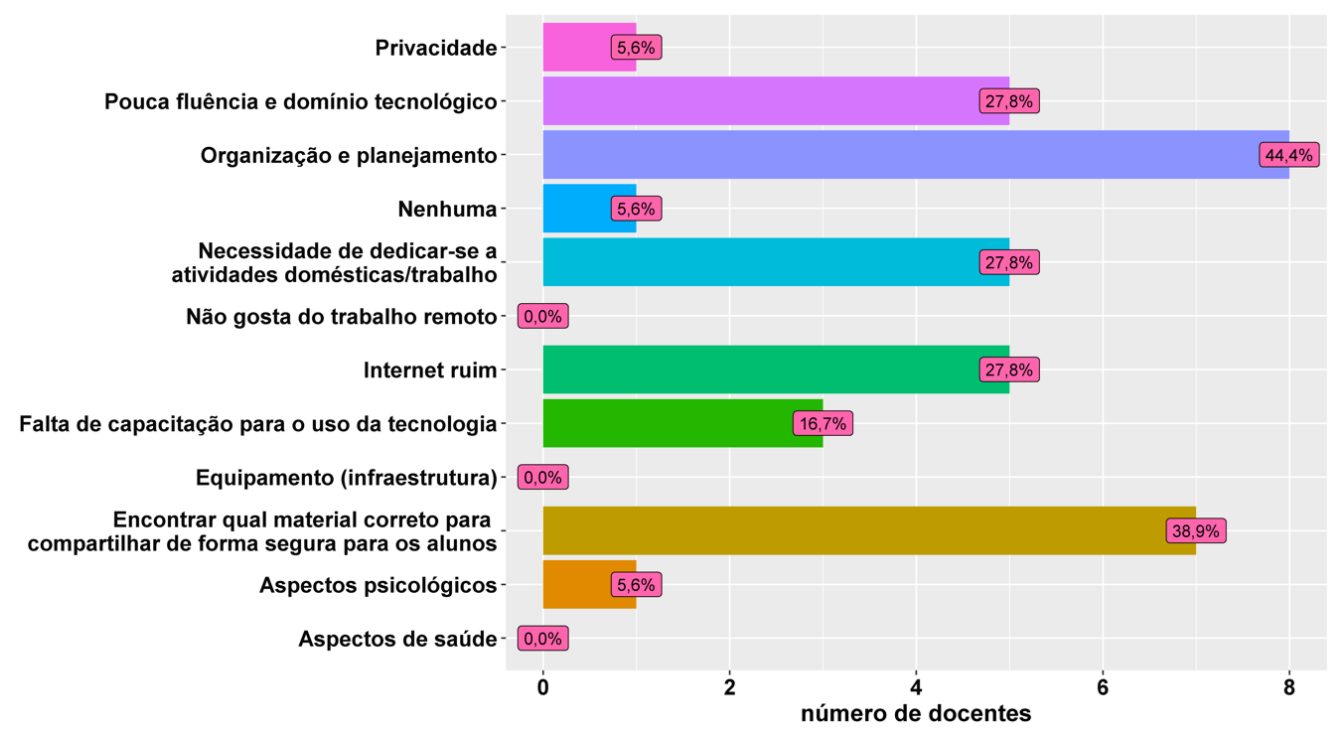

Fonte: Elaborado pelos autores. 
A maior percentagem de discordância foi de 3 (17\%), nas questões sobre a organização do tempo para executar as aulas e atividades síncronas remotas e sobre a produtividade do processo ensino-aprendizagem durante o período remoto.

Em relação aos desafios, podemos notar no Gráfico 4 que os maiores enfrentados pelos professores foram em relação à organização e ao planejamento (44,4\%) e sobre encontrar material para compartilhar com os alunos (38,9\%). Em contrapartida, infraestrutura, não gostar do trabalho remoto e questões de saúde não foram fatores impeditivos para nenhum dos docentes.

Outro aspecto importante observado nos resultados foi, quando comparados com os alunos, a baixa taxa de relato de problemas psicológicos entre os docentes (5,6\%). Além disso, a grande parte dos professores, similar aos estudantes, selecionou mais de um desafio durante o ensino remoto, com uma média de 1,94.

\section{DISCUSSÃO}

Torna-se evidente que os discentes avaliam a modalidade do ensino remoto como razoável, com diversos fatores que dificultaram que ela fosse mais exitosa, como a adaptação e organização para a nova modalidade de aprendizagem (com amplitude inédita na instituição) e aspectos psicológicos. Esses dados podem refletir o processo de adaptação às tecnologias e o início da percepção dos seus ganhos, o que pode ser comprovado no estudo de Oliveira et al. ${ }^{9}$. De acordo como esses autores, as tecnologias podem trazer ganhos para a capacitação profissional, mas não substituem as atividades presenciais.

Inicialmente, é interessante observar a influência de questões relacionadas às tecnologias empregadas na qualidade do aprendizado no ensino remoto, pois, apesar de a maioria dispor de hardware e conexão à internet adequados, além de ter segurança ao utilizar ferramentas digitais e já ter participado de cursos on-line, a infraestrutura tecnológica não está entre as principais barreiras para o desenvolvimento das disciplinas no ensino remoto. Isso pode estar associado, como indicado em estudos ${ }^{9,10}$, à maior habilidade desses estudantes com as tecnologias, o que fez com que não fosse um fator determinante que dificultaria a adaptação para o ensino remoto.

Para além do domínio tecnológico, a limitação da interação com os professores, os pacientes e seus pares - essencial para o desenvolvimento de duas habilidades profissionais ${ }^{11}$ - pode ter sido um determinante importante para a avaliação dos alunos. Como observado na análise do aprendizado, satisfação e dificuldades dos estudantes, as principais barreiras foram adaptar-se ao trabalho remoto, encontrar a organização e o planejamento adequados para essa nova realidade e lidar com a demanda de conteúdos e atividades. Isso ocorreu, naturalmente, após meses sem uma rotina de atividades acadêmicas, e a retomada poderia ocorrer com dificuldades. Somam-se a isso as novas condições de ensino-aprendizagem que surgiram com a pandemia: todas as interações entre os alunos, seus pares e professores passaram a ser intermediadas pela tecnologia, ocorrendo síncrona e assincronamente, quando geralmente o contato era presencial e em tempo real, permitindo a construção de vínculos e o desenvolvimento de habilidades que não são desenvolvidos da mesma forma virtualmente ${ }^{12}$.

As questões psicológicas também foram determinantes para os resultados constatados. Cerca de 113 estudantes (40\%) afirmaram que elas representaram desafios no desenvolvimento das atividades, o que está associado à ansiedade e é decorrente de todas as incertezas que a interrupção e a retomada incipiente das atividades acadêmicas imprimem sobre seu futuro profissional ${ }^{13}$. Além disso, não se podem marginalizar os impactos diretos da pandemia: o estresse e a preocupação generalizada, com os riscos de contaminação e infecção de si próprios ou familiares, a perda de entes queridos, além da percepção dos efeitos sociais, econômicos e sanitários na comunidade na qual estão inseridos ${ }^{14}$.

Em relação aos professores, é importante destacar que existiram algumas incoerências quando comparadas as avaliações feitas pelos alunos em relação ao período de ensino remoto considerando seus respectivos perfis tecnológicos. Nesse sentido, é válido apontar as três incongruências principais percebidas, que dizem respeito à experiência prévia, à insegurança e ao espaço apropriado para ensino/aprendizagem. Assim, destaca-se que, apesar de a percentagem de professores que referiram experiência prévia no ensino on-line ser menor que a percentagem de alunos, apesar de a percentagem de professores que declararam ter insegurança em lecionar no ensino remoto ser menor que a percentagem referida pelos alunos e apesar de a percentagem dos professores que afirmaram ter uma rotina de isolamento e não ter em sua moradia um ambiente apropriado para realização das suas atividades ser menor quando comparada à dos alunos que mencionaram a mesma situação, a avaliação geral do ensino remoto feita pelos professores foi majoritariamente positiva em todos os aspectos avaliados, ao contrário do que se percebeu na avaliação feita pelos alunos.

Sobre as possíveis associações que podem justificar essas incongruências, há alguns desafios que foram mais referidos pelos alunos em relação aos professores. O primeiro deles concerne aos aspectos psicológicos como desafio enfrentado no desenvolvimento das disciplinas no ensino remoto. Um segundo desafio que pode explicar as incongruências percebidas diz respeito à infraestrutura disponível durante o período do ensino remoto. Isso se torna visível quando se observa que, enquanto para $11 \%$ dos alunos a infraestrutura foi um desafio enfrentado, para nenhum dos docentes esse fator foi um impeditivo. 


\section{CONCLUSÃO}

O aumento da utilização do ensino remoto por diversas organizações educacionais, impulsionado devido à necessidade de distanciamento social no ano de 2020, evidenciou os desafios e possíveis benefícios dessa modalidade que pode ter um papel transformador na sociedade atual.

A experiência relatada pelos docentes e alunos neste artigo, embora existam algumas dificuldades, foi, de maneira geral, uma avaliação positiva do ensino remoto. Porém, apesar de a maioria dos professores e estudantes relatar satisfação com o ensino remoto, algumas questões importantes surgiram. Por exemplo, de acordo com grande parte dos alunos, eles não renderam tanto nos estudos como em um semestre presencial. Além disso, houve problemas de organização e planejamento de ambos os grupos. Por conta dessas questões, diversos outros desafios ocorreram na realização do semestre remoto.

Os diversos fatores relacionados à tecnologia, à organização dos estudantes e à saúde mental deles devem ser considerados no planejamento dos próximos semestres, pois, até que a situação de saúde volte ao normal, os próximos semestres letivos terão todos os componentes teóricos do curso de Medicina trabalhados remotamente, ao menos com a maioria na modalidade híbrida. É provável que os estudantes desenvolvam uma curva de aprendizagem e consequente adaptação, o que pode atenuar algumas das dificuldades observadas.

O artigo também demonstra que diversos fatores devem ser considerados para se dar continuidade ao ensino remoto, um dos mais importantes sendo os aspectos psicológicos dos estudantes e professores, tendo a necessidade da execução de ações para evitar e mitigar essa questão, principalmente em um contexto de pandemia. Portanto, existe a necessidade de dar seguimento a este estudo nos semestres remotos seguintes, para poder haver a monitorização da qualidade e do aperfeiçoamento do EaD, com base no feedback dos semestres que se passam, podendo assim otimizar o ensino remoto e melhorar a experiência tanto dos alunos como dos professores nessa modalidade.

\section{CONTRIBUIÇÃO DOS AUTORES}

Amadeu Sá de Campos Filho contribuiu com a concepção do projeto e análise e interpretação dos dados, com a redação do artigo e revisão crítica relevante do conteúdo intelectual, e na aprovação final da versão a ser publicada, além de ser responsável por todos os aspectos do trabalho na garantia da exatidão e integridade de qualquer parte do manuscrito. João Marcelo Duarte Ribeiro Sobrinho, Ricardo Fusano Romão, Carlos Henrique
Nascimento Domingues da Silva, Júlio Cesar Pereira Alves e Rodrigo Lins Rodrigues contribuíram com a análise e interpretação d os dados, além de participarem da redação do artigo.

\section{CONFLITO DE INTERESSES}

Declaramos não haver conflito de interesses.

\section{FINANCIAMENTO}

Declaramos não haver financiamento.

\section{REFERÊNCIAS}

1. Farias PAM, Martin ALAR, Cristo CS. Aprendizagem ativa na educação em saúde: percurso histórico e aplicações. Rev Bras Educ Med. 2015;39:143-50.

2. Gomes AS, Pimentel EP. Ambientes virtuais de aprendizagem para uma educação mediada por tecnologias digitais. Informática na Educação: ambientes de aprendizagem, objetos de aprendizagem e empreendedorismo. Porto Alegre: Sociedade Brasileira de Computação; 2021. (Série Informática na Educação Ceie-SBC) [acesso em 20 de maio de 2021]. Disponível em: https://ieducacao.ceie-br.org/ava.

3. Brasil. Resolução CNE/CES no 4, de 7 de novembro de 2001. Institui Diretrizes Curriculares Nacionais do curso de graduação em Medicina. Diário Oficial da União; 2001. p. 38.

4. Gomes AP, e Rego S. Transformação da educação médica: é possível formar um novo médico a partir de mudanças no método de ensinoaprendizagem? Rev Bras Educ Med. 2011;35:557-66.

5. Santos BM, Cordeiro MEC, Schneider IJC, Ceccon RF. Educação médica durante a pandemia da Covid-19: uma revisão de escopo. Rev Bras Educ Med 2020;44(supl 1):e139.

6. Kukreti R, Dani R. Analyzing role of university/institute support and organizational environment in industrial training satisfaction of hospitality students: with reference to Uttarakhand. International Journal of Recent Technology and Engineering. 2020;8:2277-3878.

7. Novaes MA, Machiavelli JL, Mello M, Coutinho O. Ambiente virtual de aprendizagem: uma estratégia para incorporação da informática no currículo de medicina. Rev Bras Educ Med. 2009; 33(4 supl 4):224.

8. Campos Filho AS, Novaes MA, Gomes AS. The Mental Workload Evaluation in Visualizing Telehealth Indicators on Three-Dimensional Interface. Telemed J E Health. 2018;24(6):442-448.

9. Oliveira SS, Postal EA, Afonso DH. As escolas médicas e os desafios da formação médica diante da epidemia brasileira da Covid-19: das (in)certezas acadêmicas ao compromisso social. APS em Revista. 2020;2(1):56-60.

10. Falbo $\mathrm{GH}$, Araújo $\mathrm{CAL}$, Souza ES. Educação médica em tempos de Covid-19: a experiência da Faculdade Pernambucana da Saúde. Rev Bras Saúde Mater Infant. 2021;21:539-44.

11. Afonso DH, Postal EA, de Oliveira SS, Pereira DVR, Grosseman S, Batista NA, et al. Análise da Associação Brasileira de Educação Médica sobre os desafios da residência médica na pandemia da Covid-19. Health Residencies Journal. 2020;1(3):6-15.

12. Gomes VTS, Rodrigues RO, Gomes RNS, Gomes MS, Viana LVM, Silva FS. A pandemia da Covid-19: repercussões do ensino remoto na formação médica. Rev Bras Educ Med. 2020;44(4): e114.

13. Rodrigues BB, Cardoso RRJ, Peres CHR, Marques FF. Aprendendo com o imprevisível: saúde mental dos universitários e educação médica na pandemia de Covid-19. Rev Bras Educ Med. 2020;44(sup.1):e0149.

14. Silva AC, Martin DS, Santiago AT, Santos OS, Paes CJO, Silva AC, et al. O impacto psicológico da pandemia de Covid-19 nos acadêmicos de medicina da região de Carajás. Brazilian Journal of Health Review. 2020;3:19731-47. 